\title{
Primary intratracheal neurilemmoma in a ten-year-old girl: case report and literature review
}

Lei $\mathrm{Wu}^{1}$, Micun Sha ${ }^{2}$, xiling $\mathrm{wu}^{3}$, Jing $\mathrm{Bi}^{1}$, Min Yang ${ }^{1}$, and Zhimin $\mathrm{Chen}^{1}$

${ }^{1}$ Zhejiang University School of Medicine Children's Hospital

${ }^{2}$ Suqian People's Hospital of Nanjing Drum-tower Hospital Group

${ }^{3}$ Children's Hospital, Zhejiang University School of Medicine

November 23, 2020

\begin{abstract}
Primary intratracheal neurilemmoma is rare in children. Here, we reported a case of tracheal neurilemmoma in a 10-year-old girl. She had recurrent cough, dyspnea, and tachypnea. Magnetic resonance imaging revealed a soft-tissue mass was located on the right lateral posterior wall of the trachea. A multidisciplinary operation was performed. Immunohistochemical analysis demonstrated a benign neurilemmoma. Her clinical symptoms and signs improved. We reviewed the clinical features and surgical procedures of ten children with intratracheal neurilemmoma reported in literature. Radiographic techniques and bronchoscopy are helpful for diagnosis of the disease. Long-time follow-up is required.
\end{abstract}

\section{Hosted file}

Manuscript.pdf available at https://authorea.com/users/378118/articles/494680-primaryintratracheal-neurilemmoma-in-a-ten-year-old-girl-case-report-and-literature-review
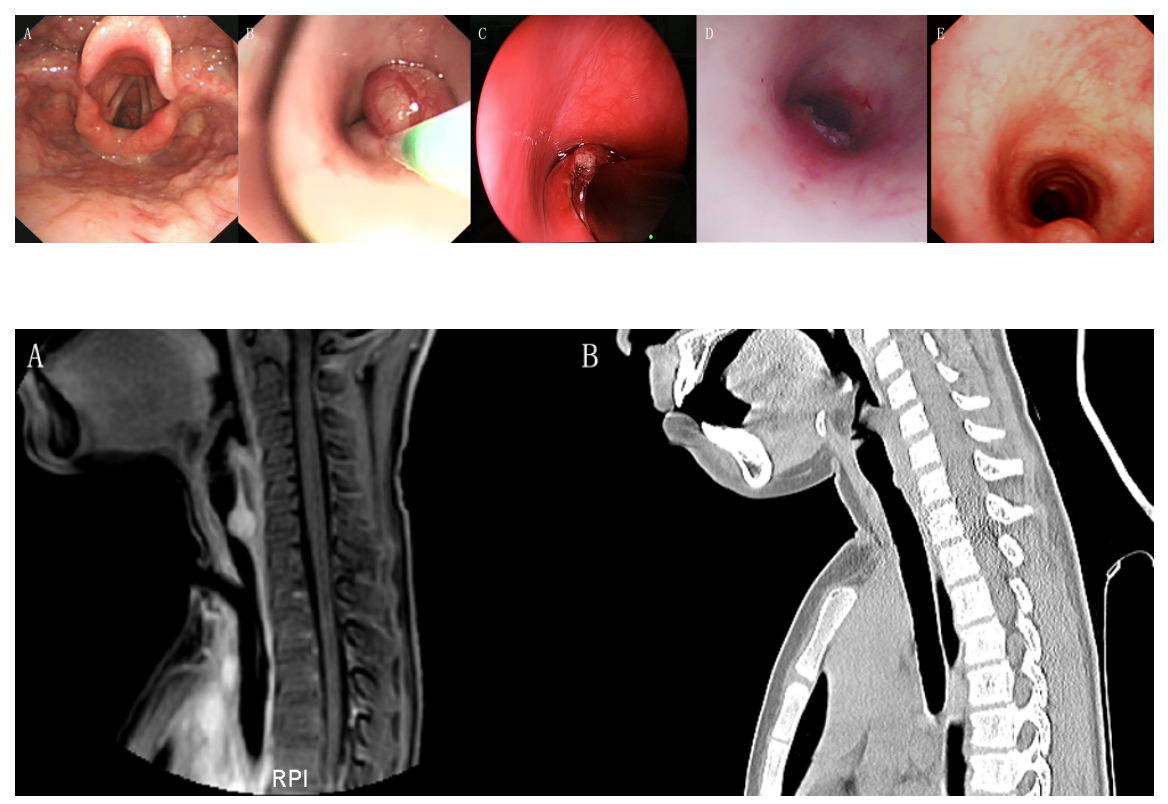


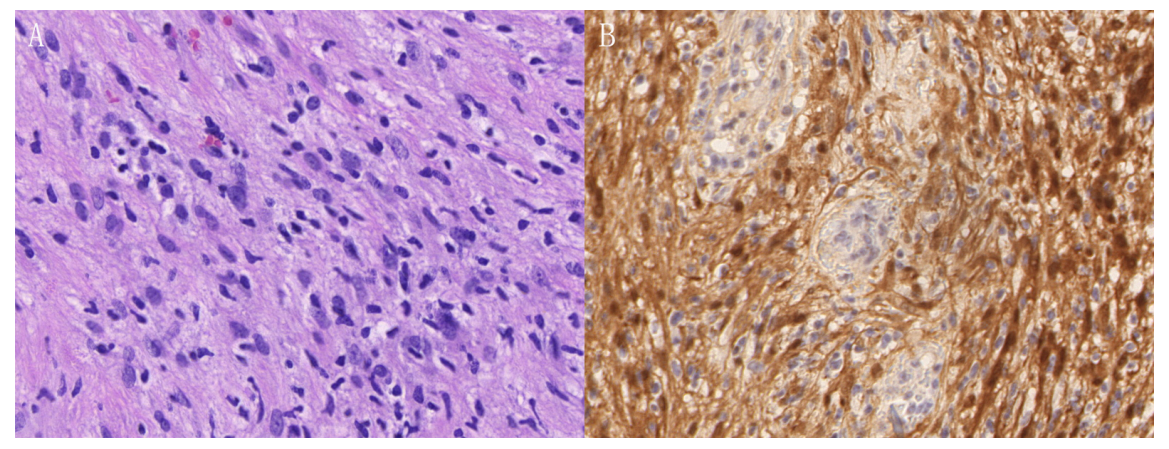

